\title{
Diretrizes para proteção do conhecimento: um estudo de caso em uma universidade do Estado do Paraná
}

\section{Guidelines for protection of knowledge: a case study in a university of Parana State}

\author{
Adriana Aguillera Gonçalves ${ }^{1}$, Maria Inês Tomaél ${ }^{2}$ \\ ${ }^{1}$ Universidade Tecnológica Federal do Paraná - UTFPR, Brasil \\ 2 Universidade Estadual de Londrina - UEL, Brasil
}

Autor para correspondência/Mail to: Adriana Aguillera Gonçalves adrianaagui@utfpr.edu.br

Recebido/Submitted: 23 Jun. 2015; Aceito/Approved: 02 Ago. 2015

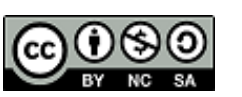

\begin{abstract}
Copyright (C) 2015 Gonçalves \& Tomaél. Todo o conteúdo da Revista (incluindo-se instruções, política editorial e modelos) está sob uma licença Creative Commons Atribuição-NãoComercial-Compartilhalgual 3.0 Não Adaptada. Ao serem publicados por esta Revista, os artigos são de livre uso em ambientes educacionais, de pesquisa e não comerciais, com atribuição de autoria obrigatória. Mais informações em
\end{abstract} http://ojs.c3sl.ufpr.br/ojs2/index.php/atoz/about/submissions\#copyrightNotice.

\begin{abstract}
Resumo
Introdução: O presente estudo procurou verificar as diretrizes que regulamentam a proteção do conhecimento em uma Universidade no Estado do Paraná, favorecendo o surgimento de inovações no meio acadêmico.

Método: O método empregado foi o estudo de caso e a coleta de dados foi realizada em duas etapas. Na primeira etapa, foi realizada uma pesquisa documental, que possibilitou a análise de normas jurídicas que contém as diretrizes para a proteção do conhecimento na Universidade estudada. Na segunda, por meio de entrevistas com pesquisadores e gestores de uma Agência de Inovação, foi possível reunir considerações acerca das normas jurídicas existentes para proteção do conhecimento, abrangendo aspectos normativos e a visibilidade do documento no referido universo. Para o tratamento das informações coletadas, utilizou-se da Técnica de Análise de Conteúdo.

Resultados: Os resultados revelam que as diretrizes de proteção do conhecimento existentes estão voltadas essencialmente para a participação dos inventores nos ganhos financeiros. Outros aspectos importantes da propriedade intelectual, como a questão do sigilo, a busca da informação tecnológica, acordos de confidencialidade, normatizações quanto à publicação e o patenteamento, ainda não são contemplados nas diretrizes de proteção ao conhecimento da referida instituição.

Conclusão: Conclui-se que possivelmente, a ausência dessas diretrizes colabore para a falta de sensibilização dos pesquisadores para a proteção do conhecimento e inovação, o que é visível no ambiente estudado. Pesquisadores se mostram desprovidos de condições e informações que caracterizem e subsidiem uma cultura voltada para o processo inovativo.
\end{abstract}

Palavras-chave: Proteção do Conhecimento; Diretrizes para Inventores; Propriedade Intelectual; Universidade Pública; Agência de Inovação

\begin{abstract}
Introduction: Innovation derived from scientific knowledge is possible when it is protected by intellectual property instruments such as the patent. The act of patenting knowledge ensures the rights of the stakeholders against misappropriation, enables the secure sharing, and contributes to technological development. Thus, it is essential to have guidelines in order to guide the protection of knowledge aiming at innovation. These instructions must encompass aspects related to confidentiality, rights and financial participation for those involved in this process. Within this scope, this study aims to determine the guidelines which regulate the protection of knowledge at an university in the State of Paraná, favoring the emergence of innovations in the academic environment.

Method: A documentary research was carried out at the first stage which enabled the analysis of legal rules containing the protocols for protection of knowledge in the University. At the second one, it was possible to gather considerations of existing legal rules for protection of knowledge through interviews with researchers and managers of an Innovation Agency, covering regulatory issues and the visibility of the document in that environment. A content analysis technique was used for treating the collected information.

Results: The guidelines for knowledge protection existing in the organization focus primarily on the participation of inventors in financial gains. Other important aspects of intellectual property, such as confidentiality, the pursuit of technological information, confidentiality agreements, normalization referring to the publication, and patenting are not included in the guidelines for protection of knowledge for this institution.

Conclusion: It is concluded that possibly the absence of such guidelines collaborate with the lack of awareness of researchers for protection of knowledge and innovation, which is visible in the studied environment. Researchers are also lacking conditions and information which characterize and support a culture focused on the innovative process.
\end{abstract}

Keywords: Protection of knowledge; Guidelines for inventors; Intelectual property; Public university; Innovation Agency

\section{INTRODUÇÃO}

Referencial de desenvolvimento, o conhecimento tem sido reconhecido pela sociedade moderna como um recurso econômico proeminente, a força motriz da prosperidade de um país, já que pela sua própria natureza incita o surgimento de inovações. A inovação, por sua vez, decorre de conhecimento científico (Staub, 2001), o que eleva o conceito da universidade como instituição primordial de geração de conhecimentos por meio da tríade ensino, pesquisa e extensão.

Sobre este viés, a gestão do conhecimento científico com foco na sua proteção, tende a potencializar substancialmente a participação das universidades no enfrentamento de um país mais desenvolvido economicamente. Este fato, aliado às políticas públicas de apoio e incentivo à inovação tecnológica e uma maior integração da 
universidade com o setor produtivo, poderá favorecer a institucionalização da cultura da propriedade intelectual no meio acadêmico.

A gestão da propriedade intelectual sugestiona a disseminação e o compartilhamento do conhecimento, garantindo, sobretudo, os direitos do autor/inventor. Com efeito, definições de diretrizes que visem à proteção do conhecimento com foco na inovação se fazem imprescindíveis, abrangendo desde questões de sigilo no desenvolvimento das pesquisas até atribuições de direitos sobre as criações intelectuais e a participação financeira dos envolvidos no que se refere à exploração comercial.

Certamente, o estabelecimento de uma política de propriedade intelectual poderá contribuir para a sensibilização da comunidade científica quanto aos benefícios da proteção do conhecimento para o inventor, para a universidade e para a sociedade (Fujino \& Stal, 2007; Rosário, 2006). Um novo olhar dessa comunidade poderá ser vivificado em prol da geração de pesquisas que venham a gerar inovações, as quais poderão representar a efetiva transferência do conhecimento da universidade para a sociedade.

Neste contexto, esta pesquisa teve como objetivo verificar as diretrizes que regulamentam a proteção do conhecimento em uma universidade no Estado do Paraná, e que possam favorecer o surgimento de inovações no meio acadêmico. Para tanto, foi desenvolvida uma pesquisa descritiva de caráter qualitativo por meio do estudo de caso envolvendo pesquisadores que solicitaram patentes no período de 2008 a 2010 e gestores da Agência de Inovação desta Universidade. A coleta de dados foi realizada em duas etapas. A primeira buscou, por meio da pesquisa documental, analisar as normas jurídicas que contêm as diretrizes de interesse interno e que são voltadas à proteção do conhecimento na Universidade estudada. A segunda etapa possibilitou, por meio de entrevistas, reunir considerações acerca das normas jurídicas existentes para proteção do conhecimento, abrangendo aspectos normativos e a visibilidade dessas normas no âmbito desta universidade. Para o tratamento das informações coletadas, utilizou-se a técnica de análise de conteúdo de forma a detalhar mais exaustivamente o objeto estudado.

\section{A proteção do conhecimento e a patente como mecanismo de proteção}

$\mathrm{Na}$ atualidade, vive-se um período em que o conhecimento se tornou a nova moeda de troca na sociedade moderna, tornando-se um bem intangível de alto valor. Nessa perspectiva, o conhecimento deve ser protegido, possibilitando a geração de inovações e garantia dos direitos de propriedade intelectual do inventor/autor. A proteção da propriedade intelectual assegura ao autor o privilégio de exploração comercial de suas criações por período limitado de tempo, impedindo que terceiros o façam sem prévia autorização do autor (Fujino, Stal, \& Plonski, 1999).

A proteção do conhecimento no âmbito da propriedade industrial trata da proteção jurídica dos bens incorpóreos aplicáveis de forma prática na indústria. Scudeler (2007, p. 36) ressalta que a propriedade industrial envolve “[...] a proteção das patentes, segredos industriais, desenhos industriais, marcas, indicações de procedência e geográficas, know-how, além de repressão à concorrência desleal”. Para Saénz e García Capote (2002, p. 104), a propriedade industrial abrange, além das invenções, modelos de utilidade, modelos industriais, "as marcas de fábrica ou de comércio, as marcas de serviço, os nomes comerciais, as denominações de origem, as indicações de procedência e a proteção contra a concorrência desleal", formas essas de proteção que favorecem a indústria e o comércio.

No Brasil, a instituição responsável pela concessão de patentes e registros de marca, desenho industrial e indicação geográfica é o Instituto Nacional da Propriedade Industrial (INPI) (Silveira, 2005). A legislação que regulamenta a propriedade industrial é a Lei n. 9.279, de 14/05/1996, Lei da Propriedade Industrial, e a Lei n. 9.456, de 25/04/1997, Lei de Cultivares. É importante destacar que os direitos relativos à propriedade industrial envolvem novidade e desenvolvimento técnico utilizando atividade inventiva, sempre com aplicabilidade industrial (Bocchino, Conceição, \& Gauthier, 2009).

O inventor e/ou titular do conhecimento protegido terá condições de resguardar os seus direitos sobre suas criações, como por exemplo: proibir terceiros, sem o seu consentimento, de produzir, utilizar, vender ou importar a sua invenção, modelo de utilidade ou desenho industrial; impedir que terceiros reproduzam ou imitem a sua marca; tomar medidas contra aqueles que estejam fabricando, importando, exportando, vendendo, expondo, oferecendo a venda ou mantendo em estoque produto que apresente falsa indicação geográfica; entre outros (Araújo, Barbosa, Queiroga, \& Alves, 2010).

As patentes atendem a estas necessidades protegendo os direitos do inventor/autor, maximizando a geração de novos conhecimentos por meio da divulgação de informações técnicas, incentivando, portanto, a inovação. A lógica implícita nas patentes é estimular o investimento em invenções e inovações e a disseminação de informações tecnológicas (United Kingdom, 1996).

A comprovação da novidade e aplicabilidade de uma invenção dá origem a uma patente. É importante salientar que o termo "patente" deve ser considerado em dois sentidos: como documento que se denomina "patente", e 
como o conteúdo da proteção conferida por este documento (Saénz \& García Capote, 2002). Segundo os autores, a patente enquanto documento

[r]epresenta um direito concedido pelo Estado a um inventor, em troca da divulgação de sua invenção; esse direito é reconhecido mediante um documento legal emitido por uma agência oficial nacional responsável por esses assuntos, no qual se provêem (sic) os detalhes técnicos de uma invenção e se descreve a área de proteção legal da mesma. (Saénz \& García Capote, 2002, p. 104)

Em outras palavras, Amadei e Torkomian (2009, p. 10) afirmam que "a patente é um título de recompensa ao inventor" e se concedida, possibilita muito mais segurança nas negociações entre o inventor e a parte interessada na aquisição de uma tecnologia, passível de ser aplicada em algum setor industrial.

Em relação ao conteúdo da patente, pode-se dizer que representa uma preciosa fonte de informação tecnológica que oferece vantagens inestimáveis para geração de novas tecnologias (Garcia, 2006). Além de proteger o inventor, a patente facilita a geração de novas invenções por terceiros, levando o seu próprio titular a prosseguir inventando para se manter a frente de seus competidores. A propriedade temporalmente limitada e o interesse público da informação divulgada acabam por tornar a patente um instrumento estratégico de promoção do desenvolvimento tecnológico (Macedo \& Barbosa, 2000).

Verspagen (2006, p. 610) argumenta que pode ser verificado um grande paradoxo no sistema de patentes, tendo em vista que, por um lado, ele visa instigar o desenvolvimento de novos conhecimentos, mas por outro, o monopólio legal de uma patente acaba por constituir uma restrição a livre circulação do conhecimento. Contudo, ao estimular o desenvolvimento de novos conhecimentos, as patentes acabam por incentivar o investimento em inovação e invenção, haja vista a existência de um monopólio temporário que assegura a divulgação de informações técnicas (United Kingdom, 1996).

O monopólio temporário, visto muitas vezes como impedimento da livre circulação do conhecimento, se faz indispensável no processo de inovação. Caso contrário, os inventores/criadores não teriam seus direitos de propriedade intelectual garantidos e nem o direito de explorar comercialmente sua invenção por um determinado período de tempo.

As patentes são categorizadas em duas modalidades. Uma é chamada de patente de invenção (PI), a outra, patente de modelo de utilidade (MU). A primeira refere-se a produtos ou processos absolutamente novos e originais, que não decorram da melhoria daqueles já existentes. Já a segunda categoria é o oposto, diz respeito a aperfeiçoamentos em produtos preexistentes, que melhoram sua utilização ou facilitam o seu processo produtivo (Jungmann \& Bonetti, 2010).

Apresentadas as principais formas de proteção do conhecimento dentro da modalidade de propriedade industrial e verificando, assim, sua importância no meio acadêmico, constata-se que a propriedade intelectual se configura em uma importante ferramenta de gestão da tecnologia. Este valor pode ser evidenciado por meio de pedidos de patentes e registros de desenho industrial, marca e indicações geográficas, os quais possibilitam ter uma ideia de quais tecnologias estão sendo produzidas em suas instalações. Além disso, ajuda no processo de controle e transferência dessas tecnologias para o mercado consumidor quer seja pela venda de titularidade ou pelo licenciamento (através de contratos) (Cherubini, 2009).

\section{Políticas de gestão da propriedade intelectual e as universidades}

As políticas podem ser entendidas como um conjunto de diretrizes que poderão orientar uma pessoa ou organização, uma área ou uma disciplina. Podem ser consideradas, ainda, planos de ação preestabelecidos para um determinado fim, além de simbolizar regras, estratégias, regulamentos, interesses e/ou decisões. Nesse contexto, Almeida (2000, p. 6) enfatiza que: "As políticas [...] são planos gerais de ação, guias genéricos que estabelecem linhas mestras, orientam a tomada de decisão e dão estabilidade à organização".

Inhaez (2006, p. 106) ressalta que:

As políticas são baseadas nos usos e costumes da organização, de forma a orientar as operações do dia-a-dia de cada um dos seus membros, ou, melhor dizendo, as ações administrativas dos que nela atuam. Servem de orientação para a decisão gerencial ou para a supervisão das ações dos subordinados. Elas envolvem as ações operacionais dizendo o que pode ser feito e como deve ser feito. O ideal é que elas estejam formalizadas com o aval da alta administração e permeiem toda a organização.

As políticas se consolidam em mecanismos preponderantes de orientação e sensibilização para determinadas ações. Nesse sentido, políticas que veiculem o conhecimento enquanto recurso de ascensão e desenvolvimento industrial e tecnológico se fazem prementes nas universidades. O estabelecimento dessas políticas no meio acadêmico, vislumbrando a proteção do conhecimento com vistas a possibilitar a inovação, deve ser discutido e formalizado para que a cultura da propriedade intelectual seja implementada efetivamente e os esforços da 
comunidade científica sejam também direcionados para transformação do conhecimento em produtos, serviços e processos inovadores.

Reforçando o papel das políticas nesse âmbito, Fujino et al. (1999, p. 46) salientam "a intensidade do processo de transformação do conhecimento gerado na universidade em produtos e processos que beneficiem a sociedade depende da política de proteção do conhecimento vigente na universidade”. A política de patentes como estratégia de fortalecer o tema propriedade intelectual na universidade é apontada por Rosário (2006, p. 15) que exalta a "[...] necessidade de desenvolver esforços que orientem mudanças e propiciem inserção de políticas de propriedade intelectual que contribuam para disseminação e sensibilização de toda comunidade acadêmica para esse tema [...]”, promovendo a cultura da propriedade intelectual na instituição.

Em relação às finalidades das políticas pertinentes as patentes enquanto mecanismo de gestão da propriedade intelectual, Fujino e Stal (2007) explicam que por meio dessas políticas é possível alcançar um equilíbrio entre as necessidades dos inventores, da instituição, dos patrocinadores da pesquisa e do público em geral. Confirmando e complementando o exposto, Garnica e Torkomian (2009, p. 626) enfatizam que a instituição de políticas de gestão tecnológica no meio acadêmico "[...] tornou-se imprescindível para assegurar os interesses de ambas as partes e permitir uma maximização do uso das tecnologias geradas, procurando ao mesmo tempo minimizar conflitos”. Aspectos que garantem a proteção do conhecimento e sua transferência como bem intangível para a sociedade são delineados nas políticas por meio de diretrizes que possibilitarão a garantia dos direitos de todos os envolvidos no processo.

Quanto ao conteúdo das políticas de patente, Santos (2003, p. 16) traz à discussão várias questões que devem ser levadas em consideração no momento de sua concepção. Um dos aspectos, segundo a autora, está ligado a principal finalidade da patente: a garantia dos direitos de propriedade intelectual. Outra questão importante se refere à busca de informação tecnológica em bases de patentes. Sobre isso, a autora afirma que "[o]s pesquisadores universitários, de um modo geral, quando estabelecem seus projetos de pesquisa, buscam suas referências bibliográficas em periódicos e livros, e dificilmente consultam bases de patentes”. Os critérios de participação nos ganhos econômicos também devem ser contemplados, pormenorizando aspectos quanto ao repasse de recursos para o inventor e para a universidade.

Santos (2003, p. 16) ainda destaca outras diretrizes que devem ser avaliadas como proposições nas políticas que tratam da propriedade intelectual. O sigilo e os acordos de confidencialidade também constituem aspectos relevantes para a formatação da política. A normatização sobre a publicação e o patenteamento deve ser abordada prevendo responsabilidades e recompensas para o pesquisador que, por exemplo, concordar em proteger para depois publicar. Fortalecendo esse último quesito, a autora lembra que a política de pesquisa e pós-graduações das instituições deveria estar imbricada à política de propriedade intelectual. No entanto isso muitas vezes não ocorre, e "por este motivo o pesquisador não se sente obrigado a cumprir a política de propriedade intelectual estabelecida" (Santos, 2003, p 16). A falta de diretrizes alinhadas a esta causa gera, por conseguinte, conflitos de interesses individuais e institucionais devido à tradição da pesquisa individual.

Contudo, Sbragia et al. (2006) enfatizam que, além de definir políticas de proteção à propriedade intelectual e normas de licenciamento e comercialização, se faz necessária uma revisão da cultura organizacional no meio acadêmico, tendo em vista que essa ainda hoje prima pela disseminação ampla do conhecimento, situação que vai na contramão dos interesses do meio produtivo. Nesta ótica, Santos (2004, p 127) ressalta que “[...] não basta apenas uma política escrita de um escritório de transferência de tecnologia, de um núcleo de propriedade intelectual, e implementar e difundir o procedimento.[...]”; esta política tem que estar arraigada há uma política institucional de pesquisa mais abrangente, sendo absorvida, inclusive, "nas políticas governamentais".

Contribuindo diretamente com informações e ações que podem subsidiar a política de gestão da propriedade intelectual na universidade, os núcleos de inovação tecnológica estão sendo criados nas universidades especialmente para servirem de interface com o setor produtivo. Tratando da relevância dos Núcleos de Inovação Tecnológica, Pereira et al. (2009, p 138) pondera que esses núcleos se traduzem em um meio da "[u]niversidade se estabelecer definitivamente como uma instituição que tem vocação para a pesquisa e fortalecer a extensão como uma de suas práticas mais fortes; sobretudo, voltar-se ao atendimento de demandas sociais concretas”, o que viabilizará uma aproximação mais perene da sociedade.

Diretrizes claras que atendem aos interesses de todos os envolvidos no processo de proteção do conhecimento, considerando não só pesquisadores, como a universidade e a sociedade de forma geral, merecem atenção especial na atual conjuntura, servindo de respaldo para o gestor de propriedade intelectual e, ao mesmo tempo, servindo de incentivo para alavancar a inovação com a participação da universidade no país.

\section{PROCEDIMENTOS METODOLÓGICOS}

A pesquisa enquadra-se como descritiva de caráter qualitativo. O método de investigação empregado foi o estudo de caso, o qual originou a coleta de dados em duas etapas. Na primeira etapa, foi realizada uma pesquisa documental com vistas a propiciar a análise das diretrizes contidas nas normas jurídicas, de interesse interno, 
que regulamenta a participação de docentes, servidores técnico-administrativos e alunos no resultado financeiro da exploração dos direitos de propriedade intelectual da Universidade estudada. Na segunda, foram realizadas entrevistas com nove pesquisadores que solicitaram patentes no período de 2008 a 2010, com o Diretor Geral e o Coordenador de Propriedade Intelectual da Agência de Inovação de uma universidade existente no Estado do Paraná.

A análise das normas jurídicas ocorreu pela identificação das diretrizes para a proteção do conhecimento que estão contempladas na Resolução institucional em vigor, em relação às diretrizes necessárias mencionadas na literatura. Desta forma, foram listadas as principais diretrizes existentes e, em contrapartida, apresentadas algumas diretrizes pontuadas na literatura como essenciais para que a Universidade, foco do estudo, promova a cultura da propriedade intelectual e inovação no âmbito acadêmico.

Para a análise e o tratamento das informações coletadas, utilizou-se da técnica de análise de conteúdo de Bardin (2010), que possibilitou "inferências confiáveis de dados e informações com respeito a determinado contexto, a partir dos discursos escritos ou orais de seus atores e/ou autores”. Além disso, foi levado em consideração, não só a "descrição dos conteúdos", mas esses associados ao contexto, viabilizando inferências sobre as circunstâncias na sua totalidade (Martins \& Theóphilo, 2009, p 98).

De acordo com Bardin (2010, p 121), a análise de conteúdo é composta de três fases: a) pré-análise; b) exploração do material; c) tratamento dos resultados, a inferência e a interpretação. Tais fases são apresentadas a seguir, juntamente com os procedimentos realizados para o desenvolvimento do estudo:

a) a pré-análise compreendeu a coleta e organização do material (incluindo a transcrição das entrevistas) mediante uma leitura mais superficial para proceder à análise;

b) na fase seguinte - exploração dos materiais - categorizou-se os temas por meio de uma leitura exaustiva de todo material coletado, o que propiciou um agrupamento de ideias, definições, opiniões e informações que convergiu para temas comuns;

c) na terceira e última fase, a análise e reflexão do conteúdo categorizado possibilitou inferências e interpretações dos dados até então "brutos”, tornando-os significativos aos olhos do pesquisador e reveladores aos propósitos da pesquisa.

Os resultados revelaram um arcabouço de normativas de proteção do conhecimento ainda muito incipientes e pouco conhecidas pela comunidade participante do estudo.

\section{DIRETRIZES PARA PROTEÇÃO DO CONHECIMENTO: RESULTADOS DA PESQUISA}

A política de propriedade intelectual contempla as diretrizes para a proteção do conhecimento, que por sua vez, asseguram os direitos de todos os envolvidos no desenvolvimento de pesquisas que venham a gerar ativos intangíveis. Garnica e Torkomian (2009, p 630) ressaltam que “[a] normatização da propriedade intelectual nas universidades se dá por meio do estabelecimento de Portarias e Resoluções que expressam as diretrizes políticas institucionais [...]". Essas diretrizes regulam as atividades das universidades relacionadas à produção de conhecimento, que em um processo de transferência de tecnologia, por exemplo, determinam a forma de comercialização dos ativos intelectuais e do conhecimento gerado no âmbito acadêmico.

A proposta de verificar as diretrizes que regulamentam a proteção no conhecimento na universidade selecionada para o estudo possibilitou a deteç̧ão de subsídios que poderão contribuir para a definição e/ou aperfeiçoamento de políticas e ações que promoverão uma maior sensibilização dos pesquisadores do universo estudado para a cultura da propriedade intelectual, favorecendo o surgimento de inovações no meio acadêmico.

As diretrizes para Proteção do Conhecimento que regulamentam a participação de docentes, servidores técnicoadministrativos e alunos a titularidade dos direitos de propriedade intelectual pertence à Universidade, podendo ser dividida com outras instituições que tenham participado do desenvolvimento de produtos e/ou processos. $\mathrm{O}$ pesquisador participante do processo é considerado autor ou inventor. Mediante o exposto, analisaram-se as diretrizes que regulamentam aspectos da proteção do conhecimento na Universidade estudada. Nas normas jurídicas já mencionadas, as diretrizes existentes contemplam aspectos sobre:

a) titularidade $\left(\operatorname{Art.~} 1^{\circ}\right.$ );

b) divisão e aplicação dos recursos financeiros (Art. $2^{\circ}$ e $\left.3^{\circ}\right)$;

c) pagamento da participação financeira (Art. $4^{\circ}$ );

d) repartição do percentual de participação entre a equipe (Art. $5^{\circ}$ );

e) concessão de licença de exploração, cessão ou transferência dos direitos de PI (Art. $6^{\circ}$ );

f) desenvolvimento de produtos ou processos em parceria com instituições externas (Art. $7^{\circ}$ ); 
g) transferência de know-how ou de tecnologia $\left(\right.$ Art. $8^{\circ}$ ). Os direitos de propriedade intelectual (Projetos de pesquisa em parceria com empresas);

h) busca da informação tecnológica em bases de patentes;

i) o sigilo e os acordos de confidencialidade;

j) licenciamento de tecnologias e patentes;

k) publicação e o patenteamento.

Clare et al. (2011) complementam a ideia de Santos ao explicitarem que uma instituição deve ter uma política que favoreça um ambiente propício para a proteção do conhecimento que será gerado ou mesmo transferido para uso prático, lembrando, porém, que esses conhecimentos devem ser de interesse público. Além de aspectos similares aos citados, os autores apontam outros que devem ser agregados às políticas de propriedade intelectual, assim como diretrizes que regulamentam:

a) orientações para funcionários e estudantes;

b) titularidade;

c) participação dos funcionários e alunos;

d) questões éticas;

e) conflito de interesses;

f) benefícios e partilha de receitas;

g) sensibilização e comunicação;

h) monitoramento das políticas.

No contexto da coleta dos dados junto aos pesquisadores, dos 11 entrevistados que participaram desta pesquisa, é importante ressaltar que dois são gestores na Agência de Inovação da Universidade estudada, sendo um o Diretor Geral e o outro o Coordenador da Divisão de Propriedade Intelectual. Os demais são pesquisadores que entraram com pedidos de patentes no período de 2008 a 2010.

Nesse sentido, 78\% (7) dos entrevistados afirmaram conhecer as normas jurídicas referentes à proteção do conhecimento da universidade; apenas $22 \%$ (2) informaram não ter conhecimento dessas normas. Dos que conhecem, ficou explícito que a maioria teve contato com essas normas, ou ainda, com o seu teor, somente na fase inicial do processo de proteção. Os entrevistados demonstram falta de conhecimento e dúvidas sobre as normativas descritas.

Uma das dúvidas está relacionada à questão da titularidade e valor estipulado da participação do docente no resultado financeiro da exploração dos direitos de propriedade intelectual. Um dos entrevistados manifestou sua indignação ao lembrar que, enquanto inventor, não é reconhecido como depositário e, além disso, na sua concepção, o pesquisador não pode fazer a negociação de um produto desenvolvido por ele. Outro ponto negativo apontado pelo mesmo entrevistado foi o valor da porcentagem da participação financeira estipulado para o pesquisador, quando da sua participação no invento. Segundo ele, "30\% para o pesquisador é muito pouco, quem teve a sacada fui eu, então não é a universidade [...]", afirmou. Por ser dele a autoria do "invento/produto", ou mesmo de uma equipe, esta porcentagem deveria ser bem maior. (Pesquisador $\mathrm{C}^{1}$.

No que diz respeito à negociação da patente, verificou-se junto à Coordenadora da Divisão de Transferência de Tecnologia da Agência de Inovação Tecnológica da Instituição estudada, que o pesquisador pode participar da negociação desde o momento que surge o interesse de alguma pessoa jurídica pela patente. Dessa forma, embora a titularidade pertença à Universidade, que dependendo do caso poderá ser até compartilhada, o pesquisador poderá participar da negociação da patente junto à unidade responsável pela transferência da tecnologia, até mesmo por se considerar que o pesquisador é o maior conhecedor do produto e/ou processo que será efetivamente transferido para a sociedade.

Sobre a participação financeira na exploração dos direitos de propriedade intelectual, as normas internas regulamentam as porcentagens de "33\% (trinta e três por cento) aos autores, a título de incentivo"; " $14 \%$ (quatorze por cento) à Administração Central”; "20\% (vinte por cento) ao fundo de apoio ao Ensino, Pesquisa e Extensão"; "33\% (trinta e três por cento) aos Departamentos ou Unidade(s) ao(s) qual(is) pertencerem os autores".

A respeito das porcentagens estipuladas quanto à participação nos resultados financeiros, o participante "K" informou que as porcentagens foram estipuladas com base na Lei de Inovação. $\mathrm{O}$ artigo $13^{\circ}$. da Lei de Inovação (BRASIL, 2004) determina que:

\footnotetext{
${ }^{1}$ As menções aos entrevistados são feitas, neste artigo, por letras do alfabeto de forma a garantir o anonimato.
} 
É assegurada ao criador participação mínima de 5\% (cinco por cento) e máxima de 1/3 (um terço) nos ganhos econômicos, auferidos pela ICT, resultantes de contratos de transferência de tecnologia e de licenciamento para outorga de direito de uso ou de exploração de criação protegida da qual tenha sido o inventor, obtentor ou autor [...].

Entretanto, uma das participantes da pesquisa ("J"), argumentou que a Universidade estudada "paga tudo" e que a porcentagem poderia ser até maior, mas, que por esta razão, está a contento. Na opinião da pesquisadora, caso o docente não se sinta contemplado pelo valor estipulado, ele deveria arcar com todos os custos e entrar com a solicitação de pedido de patente em escritório externo à instituição.

Os depoimentos deflagram não só uma falta de compreensão e desconhecimento das diretrizes apresentadas, mas uma inclinação à necessidade de readequações no referido documento, buscando com isso atender, da melhor forma possível, os anseios de todos os envolvidos no processo. Esta percepção também é clarificada na declaração do participante "A", que ao falar sobre a exploração do conhecimento, enfatizou que é um processo muito moroso. Segundo ele: "tem que passar pelo conselho da administração, tem que passar pela jurídica, não é simples o entendimento da valoração da tecnologia, portanto, o quanto vai se cobrar, tudo isso ainda é muito demorado", o que, muitas vezes, acaba por inviabilizar a exploração. De acordo com o participante, ainda não há uma clareza que facilite toda essa tramitação para exploração, pois a negociação toma um tempo excessivo devido os aspectos burocráticos da universidade, fazendo com que o parceiro acabe desistindo.

Em relação a esta manifestação, pode-se inferir que a questão da exploração é mais uma preocupação entre os entrevistados. Ainda de acordo com o Pesquisador "A", as universidades, de forma geral, executam bem os processos de proteção, mas não sabem ainda trabalhar com exploração, que segundo ele é o que mais importa, pois “a proteção é apenas o meio termo, não serve para absolutamente nada, se não for levado à exploração", afirmou.

A exploração, por sua vez, é efetivada mediante o licenciamento ou a transferência de tecnologia, que representa na prática o repasse do conhecimento gerado na Universidade para as empresas. Os resultados das pesquisas acadêmicas podem então ser transformados em novos produtos, processos e serviços (Garnica \& Torkomian, 2009), gerando, por conseguinte, benefícios econômicos e sociais, ou seja, o desenvolvimento (Araújo et al., 2010).

Percebe-se pelas entrevistas e pelas recomendações de alguns autores, que a política de proteção do conhecimento da Universidade estudada parece necessitar de uma revisão, no sentido de adequar as diretrizes existentes e normatizar novos aspectos não contemplados nas normas vigente, tais como: busca da informação tecnológica, questões de sigilo e acordos de confidencialidade, regras para publicar e patentear, questões éticas e sensibilização para proteção do conhecimento. Parece evidente também que ainda falta um entendimento maior por parte dos pesquisadores quanto às normas jurídicas existentes, deixando clara a necessidade de uma disseminação maior dessas normas, que possibilite inclusive sua compreensão. É preponderante destacar que algumas manifestações dos participantes vão ao encontro a prerrogativas já estabelecidas na Lei de Inovação. Outras políticas ainda devem ser formatadas, considerando não só a fase inicial de "proteção", que potencializa a inovação, como a efetiva exploração do "conhecimento".

\section{CONSIDERAÇÕES FINAIS}

A promoção da inovação a partir dos resultados das pesquisas realizadas no âmbito acadêmico prescreve a formulação de uma política concreta e agressiva de gestão dos bens intangíveis, que seja, inclusive, construída levando em consideração os interesses de todos os envolvidos no processo, quer sejam inventores, instituições/empresas participantes e/ou órgãos financiadores de pesquisas. O trabalho contínuo de disseminação interna desta política potencializa a cultura da propriedade nas Universidades, viabilizando diretrizes que levam a obtenção de uma meta "comum", a transformação do conhecimento em bens palpáveis e inovadores para a sociedade.

Os resultados constataram que as normas jurídicas existentes na Universidade estudada normatizam especialmente a questão da participação de docentes, servidores técnico-administrativos e alunos no resultado financeiro da exploração dos direitos de propriedade intelectual, no entanto essas normas não são amplamente divulgadas e falta compreensão dos pesquisadores em relação a alguns quesitos. Outros aspectos importantes da propriedade intelectual, como a questão do sigilo, a busca da informação tecnológica, acordos de confidencialidade, normatizações quanto à publicação e o patenteamento, ainda não são contemplados nas diretrizes de proteção ao conhecimento da referida instituição.

Outro indicador que deve ser levado em consideração pelos dirigentes da Agência de Inovação e responsáveis indiretos pelo desenvolvimento da política de gestão do conhecimento científico, é a abrangência da política, que deve permear todas as ações que envolvem pesquisa e disseminação do conhecimento. Sugere-se ainda que novas diretrizes também sejam delineadas com vistas a fortalecer a integração e o relacionamento da Agência de Inovação com os departamentos e cursos de Pós-Graduação de forma geral, favorecendo uma harmonização 
de objetivos e princípios a partir da formulação embrionária do conhecimento, sua proteção, disseminação e exploração. 


\section{REFERÊNCIAS}

Almeida, M. C. B. (2000). Planejamento de bibliotecas e serviços de informação. Brasília: Briquet de Lemos.

Amadei, J. R. P., \& Torkomian, A. L. V. (2009). As patentes nas universidades: análise dos depósitos das universidades públicas paulistas (1995-2006). Ciência da Informação, 38(2), 9-18. Recuperado em 4 ago. 2015, de http://revista.ibict.br/ index.php/ciinf/article/view/1054/1319

Araújo, E. F., Barbosa, C. M., Queiroga, E. S., \& Alves, F. F. (2010). Propriedade intelectual: proteção e gestão estratégica do conhecimento. Revista Brasileira de Zootecnia, 39(supl. esp.), 1-10. Recuperado em 4 ago. 2015, de http://www.scielo.br/scielo.php?script=sci_arttext\&pid= S1516-35982010001300001

Bardin, L. (2010). Análise de conteúdo. Lisboa: Edições 70.

Bocchino, L. O., Conceição, Z., \& Gauthier, F. A. O. G. (2009). Propriedade intelectual: principais conceitos e legislação. $\mathrm{Cu}-$ ritiba: Agência de Inovação.

BRASIL. (2004). Lei $n^{\circ} 10.973$, de 2 de dezembro de 2004. dispõe sobre incentivos à inovação e à pesquisa científica e tecnológica no ambiente produtivo e dá outras providências.Diário Oficial da Republica Federativa do Brasil. Brasília. Recuperado em 4 ago. 2015, de http://www.planalto.gov.br/ccivil_03/_ato2004 -2006/2004/lei/110.973.htm

Cherubini, E. (2009). Modelo de referência para a proteção do conhecimento gerado e aplicado no ambiente de uma universidade pública: um estudo de caso na UTFPR (Dissertação do Mestrado em Engenharia de Produção, Universidade Tecnológica Federal do Paraná, Ponta Grossa). Recuperado em 4 ago. 2015, de http://www.pg.utfpr.edu.br/dirppg/ppgep/ dissertacoes/arquivos/120/Dissertacao.pdf

Clare, P., et al. (2011). Intellectual asset management for universities. Recuperado em 4 ago. 2015, de https:/www.gov.uk/government/publications/ intellectual-asset-management-for-universities

Fujino, A., \& Stal, E. (2007). Gestão da propriedade intelectual na universidade pública brasileira: diretrizes para licenciamento e comercialização. Revista de Negócios, 12(1), 104-120. Recuperado em 4 ago. 2015, de http://proxy.furb.br/ ojs/index.php/rn/article/view/311/298

Fujino, A., Stal, E., \& Plonski, G. A. (1999). A proteção do conhecimento na universidade. Revista de Administração, 34(4), 46-55. Recuperado em 4 ago. 2015, de http://www .rausp.usp.br/busca/artigo.asp?num_artigo=87

Garcia, J. C. R. (2006). Patente gera patente? TransInformação, 18(3), 213-223. Recuperado em 4 ago. 2015, de http://dx.doi.org/10.1590/S0103-37862006000300005

Garnica, L. A., \& Torkomian, A. L. V. (2009). Gestão de tecnologia em universidades: uma análise do patenteamento e dos fatores de dificuldade e de apoio à transferência de tecnologia no estado de são paulo. Gestão and Produção, 16(4), 624-638. Recuperado em 4 ago. 2015, de http://dx.doi .org/10.1590/S0104-530X2009000400011

Inhaez, J. A. (2006). Missão, visão, políticas e valores. In M. Marchiori (Ed.), Faces da cultura e da comunicação organizacional (p. 96-122). São Caetano do Sul: Difusão Editora.

Jungmann, D. M., \& Bonetti, E. A. (2010). A caminho da inovação: proteção e negócios com bens de propriedade intelectual: guia para o empresário. Brasília: IEL. Recuperado em 4 ago. 2015, de http://www.inpi.gov.br/sobre/arquivos/ guia_empresario_iel-senai-e-inpi.pdf
Macedo, M. F. G., \& Barbosa, A. L. F. (2000). Patentes, pesquisa \& desenvolvimento. Rio de Janeiro: Fiocruz.

Martins, G. A., \& Theóphilo, C. R. (2009). Metodologia da investigação científica para ciências sociais aplicadas (2a. ed.). São Paulo: Atlas.

Pereira, M. F., et al. (2009). Transferência de conhecimentos científicos e tecnológicos da universidade para o segmento empresarial. RAI: Revista de Administração e inovação, 6(3), 128-144. Recuperado em 4 ago. 2015, de http://dx.doi.org/ 10.5585/rai.v6i3.406

Rosário, L. C. S. M. (2006). Inserção de políticas de propriedade intelectual nas instituições de ensino superior: o caso Puc-Rio (Dissertação do Mestrado em Administração). Pontifícia Universidade Católica do Rio de Janeiro. Departamento de Administração.

Santos, M. E. R. (2003). Propriedade intelectual e comercialização de tecnologia nas instituições de ensino e pesquisa brasileiras. In Anais do 6. Encontro de Propriedade Intelectual e Comercialização de Tecnologia (p. 15-58). Rio de Janeiro: Rede de Tecnologia do Rio de Janeiro.

Santos, M. E. R. (2004). O paradoxo do sigilo no universo acadêmico. In Anais do 7. Encontro de propriedade Intelectual e Comercialização de Tecnologia. Rio de Janeiro: Rede de Tecnologia do Rio de Janeiro.

Saénz, T. W., \& García Capote, E. (2002). Ciência, inovação e gestão tecnológica. Brasília: CNI/IEL/SENAI/ABIPTI.

Sbragia, R., et al. (2006). Inovação: como vencer esse desafio empresarial. São Paulo: Clio.

Scudeler, M. A. (2007). A função social da propriedade industrial. In V. H. T. Velázquez (Ed.), Propriedade intelectual: setores emergentes e desenvolvimento (p. 35-54). Piracicaba: Equilíbrio.

Silveira, N. (2005). Propriedade intelectual (3a. ed.).

Staub, E. (2001). Desafios estratégicos em ciência, tecnologia e inovação. Parcerias Estratégicas(13). Recuperado em 4 ago. 2015, de http://seer.cgee.org.br/index.php/ parcerias_estrategicas/article/viewFile/205/199

United Kingdom. (1996). Patents, research and technology: compatibilities and conflicts. Recuperado em 4 ago. 2015, de http://researchbriefings.parliament.uk/ResearchBriefing/ Summary/POST-PN-76

Verspagen, B. (2006). University research, intellectual property rights and european innovation systems. Journal of Economic Surveys, 20(4), 607-632. Recuperado em 13 ago. 2015, de http://dx.doi.org/10.1111/j.1467-6419.2006.00261.x

Como citar este artigo (APA):

Gonçalves, A. A. \& Tomaél, M. I. (2015). Diretrizes para proteção do conhecimento: um estudo de caso em uma universidade do Estado do Paraná. AtoZ: novas práticas em informação e conhecimento, 4(1), 34 - 42. Recuperado de: http://dx.doi.org/10.5380/atoz.v4i1.41882 